\title{
George W. Bush e a Securitização do Terrorismo após os Atentados de 11 de
}

\section{Setembro de 2001}

George W. Bush and the Securitization of Terrorism after the September 11, 2001

Attacks

Natali Laise Zamboni Hoff ${ }^{1}$

\section{RESUMO}

Considerando a importância das concepções e conceitos contidos nos trabalhos da Escola de Copenhague para o desenvolvimento do Campo de estudo da Segurança Internacional, sobretudo a Teoria da Securitização, esse trabalho busca analisar a construção discursiva do terrorismo como ameaça global, através das falas de George W. Bush após os Atentados de 11 de Setembro de 2001.

Palavras-Chave: Securitização; Terrorismo; Segurança.

\begin{abstract}
Considering the importance of the conceptions and concepts in the work's of Copenhague School to the development of the International Security field of study, especially the Theory of Securitization, this work aims to analyze the discursive construction of terrorism as a global threat through the speeches of George W. Bush after the attacks of September 11th of 2001.
\end{abstract}

Key-Words: Securitization; Terrorism; Security.

\section{INTRODUÇÃO}

Reconhecendo o impacto dos atentados de 11 de Setembro de 2001 para a política externa e de segurança norte-americana, assim como a importância dos processos intersubjetivos na construção do terrorismo enquanto um problema de segurança global,

\footnotetext{
${ }^{1}$ Cursando o Mestrado em Ciência Política na Universidade Federal do Paraná (UFPR), a Especialização em Relações Internacionais Contemporâneas na Universidade Federal da Integração Latino Americana (UNILA) e bacharel em Relações Internacionais e Integração pela Universidade Federal da Integração Latino Americana (UNILA).Foz do Iguaçu, Brasil. Email: natali.hoff@gmail.com.
} 
esse artigo busca compreender o início do processo de securitização do terrorismo através dos discursos proferidos por George W. Bush após os atentados. A pesquisa se apoia na concepção de segurança discursiva presente na obra de Barry Buzan, Ole Wæver e Jaap Wilder, Security: A new Framework for Analisys (1998).

Em Security: A new Framework for Analisys é formulada a teoria da securitização, que incorpora a relação existente entre a linguagem e a realidade, adicionando, assim, aos Estudos da Segurança Internacional, a linguagem como uma importante ferramenta para a compreensão das dinâmicas de construção de ameaças, de legitimação de ações defensivas e, ainda, para a consolidação das percepções a respeito de quem é o agente a ser seguro no campo de segurança internacional. Esse movimento faz parte da chamada virada linguística e entende que a linguagem não é uma mera representação da realidade social, mas sim, parte constitutiva e integrante da concretização das ações dos atores (GOMES, 2011, p.645).

A partir dessas concepções, a linguagem passa a ocupar um lugar importante na compreensão do mundo e na conformação das regras sociais. Os discursos e narrativas são fundamentais para o entendimento de como as relações entre atores e com o meio se conformam no cenário político internacional. O construtivismo, e também a Escola de Copenhague, como uma abordagem construtivista, “(...) torna viável a teorização sobre assuntos que, usualmente, parecem não estar relacionados, já que os conceitos e proposições, normalmente utilizados para falar sobre eles, também são independentes" (ONUF, 1989 p. 58). Assim, podemos investigar atores e conexões ideacionais de segurança internacional que antes eram pouco estudados pelas abordagens hegemônicas e positivistas.

Esse trabalho trata de observar as relações existentes entre a construção discursiva do terrorismo como uma ameaça emergencial após os ataques de 2001 e as suas relações com as percepções de ameaça no cenário internacional. Para isso, serão estudados os discursos de George W. Bush após os atentados de 11 de Setembro, sob a luz da teoria da securitização, observando como o então presidente estadunidense se utilizou dos atos de fala para caracterizar o terrorismo como ameaça emergencial e estabelecer o seu combate como uma prioridade securitária mundial. Para isso, serão analisados o primeiro pronunciamento de Bush à nação após os ataques, a fala do presidente no dia 
07/10/2001 sobre a invasão do Afeganistão, o Pronunciamento direcionado à Assembleia Geral das Nações Unidas em 11/10/2001 e o discurso de junho de 2002 de West Point, no qual foram cunhadas as premissas da Doutrina Bush².

0 artigo está dividido em três seções. A primeira seção aborda a ampliação e o aprofundamento nos Estudos de Segurança Internacional após o fim da Guerra fria, explorando o advento de novas abordagens que buscavam problematizar e alargar o conceito de segurança e ainda o advento da linguagem como ferramenta de análise da segurança. A segunda seção se concentra nas contribuições da Escola de Copenhague para o debate ampliador-aprofundador dentro da segurança, sobretudo, a partir da teoria da securitização. Na terceira seção são analisados três discursos de Bush, enfatizando a importância dos atos de fala para a compreensão dos processos de construções e representações de ameaça na atualidade, buscando identificar os elementos securitizantes na argumentação do estadista estadunidense.

\section{OS ESTUDOS DE SEGURANÇA INTERNACIONAL E A LINGUAGEM COMO FERRAMENTA DE ANÁLISE}

Está seção aborda o desenvolvimento dos Estudos de Segurança Internacional (ESI), observando como os trabalhos ampliadores das décadas de 1980 e 1990 possibilitaram a abertura e o aprofundamento nos ESI (BUZAN; HANSEN, 2012, p.291), de modo que a agenda da segurança passou a incluir temáticas antes marginalizadas pelos estudos realistas. É importante ressaltar que os temas trabalhados por essas novas escolas não eram exatamente novos, contudo eram assuntos pouco explorados pelos autores tradicionalistas ou isolados em análises feitas por poucos autores, de maneira que acabavam sendo invisibilizados frente aos Estudos Estratégicos durante a Guerra Fria.

Ressaltando que o termo segurança, como o conceito norteador dos ESI foi aceito e problematizado de maneira gradual e nem sempre ocupou a centralidade no debate, fato esse que dificulta a delimitação clara do que são os ESI. Durante a Guerra Fria conceito de estratégia estava mais presente nas discussões e formulações sobre a segurança

\footnotetext{
2 Doutrina Bush é termo utilizado para designar uma série de princípios de política externa e de segurança propostos pelo presidente norte-americano George W. Bush (2001-2008) após os Atentados de 11 de Setembro de 2001. Suas concepções se amparavam no neoconservadorismo, na caracterização do terrorismo e dos Estados apoiadores do terrorismo (denominado por Bush de "Eixo do Mal" como prioridades securitárias do país e a premissa das guerras preventivas.
} 
internacional (BUZAN; HANSEN, 2012, p.34-35). Com o final da disputa bipolar, lentes analíticas preocupadas com novos tipos de ameaças, com a ampliação dos objetos a serem seguros e com a inclusão de perspectivas que consideravam as ideias, a linguagem e a cultura como assuntos de segurança, passaram a ganhar espaço nos ESI. Dentre os temas iluminados por essas novas abordagens, destaca-se a importância da linguagem para a compreensão das dinâmicas de segurança e o seu papel na construção de percepções de ameaça.

O desenvolvimento dos Estudos de Segurança foi marcado por várias fases no decorrer de sua formação enquanto uma subárea das RI. Baldwin (1995) descreve esse processo através da definição de quatro períodos distintos. 0 período entre guerras (1918-1939) foi caracterizado por se preocupar com a melhor forma de se evitar a guerra e promover a paz e a segurança no sistema internacional. A ideia de segurança estava direcionada ao objetivo de prevenir um novo conflito armado em escala mundial. No período que vai de 1945 até 1955, os ESI foram marcados por questões relacionadas à segurança enquanto valor e como um objetivo que deveria ser perseguido pelos Estados, pela ênfase no dilema de segurança ${ }^{3}$ e pelas relações entre a segurança nacional e os assuntos domésticos. 0 período de 1955-1965 é denominado como a "Era dourada" dos ESI, marcado pela intensa produção acadêmica na área. Nesse período as análises foram redirecionadas para os Estudos Estratégicos e para preocupações com as armas nucleares e com os desdobramentos da Guerra Fria (BALDWIN, 1995, p.119-123).

O quarto período diz respeito à década de 1970 e foi descrito como o período do declínio dos Estudos Estratégicos. Isso acontece em consequência da détente ${ }^{4}$ da Guerra Fria. Os estudos de segurança estavam tão focados na guerra como instrumento de política internacional, que acabaram menosprezando aspectos legais e morais envolvidos nesses processos. Outro ponto problemático foi o estabelecimento de uma estreita relação entre esses estudos e a formulação de políticas estatais, de modo que deixaram de ser vistos como intelectuais independentes e passaram a ser considerados como parte dos

\footnotetext{
3 O Dilema de Segurança foi formulado por John Herz no início dos anos 1950 e se constitui em uma "concepção estrutural na qual os Estados têm que obter por sua própria conta os meios necessários para a sua segurança, sem depender de ninguém (o que o autor chama de auto-ajuda)” (RUDZIT, 2005, p.300). Essa busca por segurança acaba por aumentar a insegurança dos outros Estados, uma vez que cada governo pode entender as medidas tomadas como ameaças em potenciais, buscando assim aumentar os seus próprios meios de defesas, gerando o dilema de segurança.

${ }^{4}$ Período no qual houve um apaziguamento nas relações entre os Estados Unidos e a União Soviética.
} 
processos decisórios nacionais. Houve ainda o crescente aumento em pesquisas sobre e para a paz nos anos de 1960-70 (BALDWIN, 1995, p.123). Com o fim da détente e a retomada das tensões e hostilidades entre as duas potências no fim da década de 1970 e início de 1980, os estudos de segurança ganham força novamente, havendo a transição na centralidade das preocupações da segurança nacional para a internacional (BALDWIN, 1995, p.124).

É importante enaltecer que durante a Guerra Fria a segurança era refletida e teorizada sob a primazia militar e de acordo com as necessidades e interesses dos Estados, essencialmente das grandes potências. Assim, a segurança era um conceito subdesenvolvido e pouco problematizado dentro dos ESI e precisava transcender as questões militares e a ligação irrestrita com o conceito de Estados Nacionais (BUZAN, 1983, p.1-6). Contudo, com o fim da Guerra Fria, a ascensão de novas problemáticas e debates das Teorias Relações Internacionais conduziram os ESI a uma série de produções teóricas contestadoras a respeito do conceito de segurança e da centralidade militar. Dessa forma, o desafio converteu-se em repensar a segurança de modo a incluir e interpretar os problemas que se conflagravam na nova ordem mundial que se estabelecia.

As correntes de pensamento que se desenvolvem no final dos anos 1980-90 iniciam o alargamento e o aprofundamento nos ESI, havendo uma "expansão do horizonte analítico para além do espectro militar, e a inclusão de outros atores como 'objetos de referência' de segurança” (BLANCO; SANTORO, 2012, 249). Os autores ampliadores/aprofundadores não apresentavam uma agenda de pesquisa coesa e integrada, divergindo quanto ao objeto de referência, a epistemologia, a metodologia e a intensidade com a qual colocavam o conceito de segurança na centralidade das análises, não havendo consenso sobre se e como a segurança deveria ser expandida e quem eram os "verdadeiros" contestadores das abordagens tradicionalistas (BUZAN; HANSEN, 2012, p.288-291).

Dentre as contribuições dos autores ampliadores/aprofundadores, podemos destacar as abordagem construtivista nos ESI, que bifurcaram-se em construtivismo convencional e construtivismo crítico. A vertente convencional analisava casos complexos de segurança estadocêntrica nacional e militar a partir de elementos ideacionais e não materiais (BUZAN; HANSEN, 2012, p.294). Apesar de concordarem com a centralidade do 
Estado para a segurança internacional, os construtivistas mantiveram a crítica ao modo de pensar e conceber a segurança nas RI, trazendo as ideias, os valores e as identidades como possíveis ferramentas para promover a violência, o expansionismo e a agressividade no comportamento dos agentes (BUZAN; HANSEN, 2012, p.299). O construtivismo em geral se preocupa em entender como o mundo social e político funciona. A abordagem construtivista se concentra na investigação social baseada em dois elementos fundamentais: sendo o primeiro relativo ao ambiente no qual os agentes agem, que seria social e material concomitantemente; e o segundo, define que esse ajuste pode proporcionar ao agentes o entendimento dos seus interesses, assim como pode constituílos (CHEEKEL, 1998, p.325-326).

O construtivismo crítico analisava "os discursos e as ligações entre a constituição de identidades históricas e discursivas, por um lado, e as políticas de segurança, por outro" (BUZAN; HANSEN, 2012, p.300). Essa abordagem criticava a manutenção do Estado como ator central e o positivismo do construtivismo convencional. Uma preocupação latente nos trabalhos dos construtivistas relacionava-se com a necessidade de estabelecer uma abordagem profunda e discursiva sobre a segurança e as identidades. Nessas análises o construtivismo se aproximava do Pós-Estruturalismo, embora reconhecessem a existência material dos atores, não os entendendo como uma construção discursiva. Entendiam que os conceitos realistas essenciais, como o interesse nacional, são construídos a partir de representações discursivas e de elementos linguísticos (BUZAN; HANSEN, 2012, p. 301-302)

Destacando que para o construtivismo os atores constroem a sociedade do mesmo modo que a sociedade os constrói, seguindo um processo contínuo e de duas vias (ONUF, 1998, p.57). Os indivíduos, que seriam os chamados "agentes", possuem a capacidade de interferência no mundo a sua volta de maneira que os espaços e os sujeitos são definidores e caracterizadores um dos outros, constituindo um processo de construção social permanente.

Os construtivistas acreditam que também as "ideias" têm características estruturais. Em primeiro lugar, as ideias - entendidas mais genericamente como conhecimento coletivo institucionalizado em práticas - são o meio e o propulsor da ação social; definem os limites do que é cognitivamente possível ou impossível para os indivíduos. Simultaneamente, praticas baseadas em conhecimento são o resultado de indivíduos que interagem e que agem propositadamente com base em suas ideias, crenças, julgamentos e interpretações pessoais (ADLER, 1999, p. 210). 
Esse interesse na relação entre as ideias, as representações e as políticas internacionais está presente na teoria da securitização. Em trabalho conjunto, Buzan, Wæver e Wilde descrevem a segurança como um tipo particular de política aplicável a uma ampla gama de problemas (BUZAN; WAEVER; WILDER, 1998). Nesse livro, os autores passam a trabalhar com uma concepção discursiva da segurança, se preocupando com a interpretação dos processos intersubjetivos envolvidos na construção e representações de ameaças e no estabelecimento das políticas de segurança dos Estados. Na próxima seção, esse tema será abordado em mais detalhes, visando através da teoria da securitização compreender os processos intersubjetivos e linguísticos que auxiliaram no estabelecimento do terrorismo como uma ameaça emergencial.

\section{A ESCOLA DE COPENHAGUE E A SEGURANÇA DISCURSIVA: A TEORIA DA SECURITIZAÇÃO}

Esta segunda parte do trabalho se dedica a apresentar os principais postulados teóricos da Escola de Copenhague. Concentrando-se essencialmente na literatura sobre a teoria da securitização, cunhada inicialmente por Ole Wæver em 1995, no artigo Securitization and Desecuritization e melhor desenvolvida subsequentemente no livro Security: a New Framework for Analisys (1998). A Escola de Copenhague reúne os trabalhos de vários intelectuais que fizeram parte inicialmente do Centre for Peace and Conflict Research, fundado no ano de 1985 na Universidade de Copenhague, que atualmente é denominado Conflitc and Peace Research Institute (COPRI). Dentre os nomes mais significativos da escola podemos destacar Ole Wæver e Barry Buzan. Pode-se afirmar que a essência do trabalho da escola encontra-se sintetizada nas obras desses dois autores. Entre as contribuições mais significativas da Escola para a segurança internacional está a teoria da securitização, as novas unidades de análise da abordagem multissetorial da segurança e os complexos regionais de segurança.

Os autores da Escola de Copenhague formularam um quadro teórico inovador, que possibilita a interpretação das continuidades e rupturas existentes no cenário internacional, auxiliando na compreensão dos acontecimentos recentes da complexa história das relações internacionais (DUQUE, 2009, p.474). A segurança é estudada a 
partir dos processos intersubjetivos que fazem parte de suas dinâmicas, havendo uma relação constante entre a materialidade e a subjetividade e o tempo histórico.

Os trabalhos da Escola de Copenhague se caracterizam por se constituírem majoritariamente a partir de problemáticas e visões europeias sobre a segurança. Jef Huysmans atribui esse fato a forma como os estudos da Escola de Copenhague buscam integrar teoria e conhecimento empírico, bem como à ligação existente entre a Escola e os estudos para a paz. (HUYSMANS, 1998, p. 484-485). A contribuição da Escola acabou por conceder fluidez ao diálogo entre as Pesquisas para a Paz, mais presentes na Europa, e os Estudos Estratégicos, marcadamente estadunidenses, havendo um impacto inédito das perspectivas europeias no mainstream do campo da segurança internacional, voltado para as produções norte-americanas (DUQUE,2009, p.475).

Inicialmente, os estudos da Escola de Copenhague se amparavam em um conceito de segurança associado à teoria realista, de modo que admitia a ascensão de novos fenômenos e agentes no tocante à segurança internacional, contudo, mantinham a primazia do Estado como ator e objeto de segurança. Buzan se ateve a uma concepção setorial sobre a segurança, na qual defendia o estabelecimento da natureza do tipo de ameaças e das vulnerabilidades de cada objeto de referência, estando ambas estreitamente relacionadas a insegurança dos atores. 0 autor enfatiza que a natureza das ameaças é de difícil definição e deveriam ser delimitadas de acordo com o setor no qual estão inseridas. Os setores descritos são o militar, econômico, político, societal e ambiental. Cada uma dessas esferas apresenta dinâmicas e problemáticas específicas, que devem ser analisadas de acordo com o seu contexto particular (BUZAN, 1983, p.73-82).

Buzan publicou em 1983 o livro People, States and Fear: The National Security Problem in International Relations, no qual discorria sobre os setores de segurança. No ano de 1991, já no contexto pós-guerra fria e como membro da Escola de Copenhague, o autor lança uma reedição do livro, que traz uma leitura mais abrangente a respeito dos problemas de segurança, retirando o destaque que foi concedido à segurança nacional na primeira edição e se atendo a importância do estudo de atores subjetivos e objetivos para a segurança internacional. 0 título do livro passou a ser, então, People, State and Fear: Agenda for International Security Studies in the Post-Cold War Era. 
A Escola voltou a modificar os seus conceitos com a publicação do livro Security: a New Framework for Analisys (1998). As pesquisas de Ole Wæver (1989; 1995) foram cruciais para isso, uma vez que conduziram a análise da segurança através do método construtivista, sobretudo a partir de uma visão discursiva para a segurança. Wæver rejeitava o positivismo que dominava a abordagem de Buzan, descartando o conhecimento de uma realidade social a priori para o estudo da segurança e dizendo que as questões securitárias seriam construídas através das práticas sociais e discursivas.

No artigo Securitization and Desecuritization (1998), Wæver apresenta uma discussão conceitual a respeito da segurança. Para ele, a segurança estava estreitamente relacionada com os processos intersubjetivos e discursivos de construção de ameaças. Outra crítica presente no artigo se referia à noção existente nas teorizações de que quanto mais segurança melhor, possibilitando um encadeamento de securitizações nas mais variadas esferas sociais. Considerando que o conceito de segurança está historicamente atrelado à defesa e ao Estado, temos como resultado que ao se abordar um problema em termos securitários, evoca-se uma imagem de ameaça-defesa, o que nem sempre resulta em resultados positivos para a resolução dos problemas referidos nesses processos (WÆVER, 1998, p.39).

Logo, a segurança pode ser definida a partir da teoria da linguagem, como um ato de fala, isto é, o próprio empreendimento discursivo torna algo objeto de segurança. Ao invocar a ideia de segurança e da eminência de uma ameaça existencial um ator reivindica o direito a utilização de medidas extraordinárias para a resolução da situação presente (WÆVER, 1998, p.45).

Kratochwil argumenta que o mundo social está intrinsicamente ligado à linguagem e sendo a linguagem uma atividade governada por regras pode fornecer um ponto de partida para a investigação das normas na vida social. As normas são atos de fala e dependem de uma comunicação bem sucedida, com capacidade de impactar o ouvinte (apud ZEHFUSS, 2004, p.99). Onuf apresenta também essa relação entre a linguagem e a ação dos agentes, através do conceito de atos de fala. Os atos de fala ganham significância, sobretudo, embasados na repetição de seu conteúdo, ou seja, quanto mais repetido for um discurso mais relevante ele se tornará para as mais diversas esferas da sociedade e maiores serão as possibilidades de tal tema se converter em uma convenção social. Recordando que uma convenção lembra aos agentes sobre as práticas recorrentes da sociedade, logo, essa 
característica faz das convenções regras, propondo aos agentes determinados comportamentos (ONUF, 1998, p. 66). A linguagem ocupa aqui papel central para a compreensão da organização social, uma vez que é através dela que são constituídos os consensos e as novas regras.

A segurança está sempre relacionada à sobrevivência e a securitização consiste no processo pelo qual uma questão é apresentada enquanto uma ameaça existencial a determinado objeto de referência. A natureza especial e emergencial de uma ameaça acaba por legitimar a utilização de medidas extraordinárias para a resolução do problema. Ressaltando que uma ameaça existencial só pode ser compreendida em relação às particularidades e necessidades do objeto de referência e do setor no qual está inserida. Em termos militares, foi convencionando-se que todas as questões dentro da área são ameaças; na esfera política as ameaças costumam estar associadas à soberania da unidade ou com a continuidade de um regime ideológico; no setor econômico as problemáticas não são tão claras e geralmente correspondem a sobrevivência de mercados e ao acesso/proteção de recursos; o campo ambiental tende a convergir para temas dos mais variados, podendo ir desde a manutenção de ecossistemas a de espécies isoladas; e por fim, o âmbito societal relaciona-se às identidades coletivas e sua conservação em situações cambiantes (WÆVER et al, 1998, p.21-22).

Avançando em sua análise, Wæver et al afirmam que a "segurança é o movimento que leva a política para além das regras estabelecidas do jogo e enquadra o problema como um tipo especial de política"5 (WÆVER et al, 1998, p.23). A securitização seria uma forma extrema da politização, sendo que qualquer assunto passa de não-politizado, ou seja, o Estado não discute e não busca lidar com o tema, para politizado, havendo a construção de debates e políticas públicas para se aferir uma resolução para a questão proposta. Todavia, quando um problema é demasiado urgente ou essencial para uma unidade (lembrando que essa urgência pode estar contida apenas nas necessidades do ator securitizante e não na realidade), pode passar a ser securitizado. Uma temática é securitizada quando há estabelecimento intersubjetivo de uma ameaça existencial, com força suficiente para se obter efeitos no quadro político. Essa conformação da existência da ameaça e da necessidade de se lidar com ela requer medidas extraordinárias, que se encontram muitas vezes fora da "política normal" (WÆVER et al, 1998, p.23-25).

5 Tradução livre da autora: "Security is the movie that takes politics beyond the establishd rules of the game, and frames the issue either as a special kind of politics..." 
Frente a essas colocações, fica evidente que os processos argumentativos e semióticos são fundamentais para a compreensão da construção de ameaças e, consequentemente, da segurança internacional. Para se aprofundar nisso é preciso então estudar os discursos de securitização e as constelações políticas que os proferiram, buscando investigar quais as ferramentas retóricas com efeitos suficientes para convencer a audiência de sua validade. A argumentação dos agentes securitizantes tocará na noção de prioridade e urgência do problema, de modo que as regras e procedimentos convencionados possam ser ignorados (WÆVER et all, 1998, p.25) 0 objeto é colocado como existencialmente ameaçado em busca de obter o consentimento da audiência para a tomada de decisão rápida e desvinculada dos padrões de comportamentos utilizados para os temas politizados.

A securitização possui uma lógica clara, contudo, há limites para a sua execução. Nem todo discurso que pretende elevar uma questão da política normal para a emergencial acaba bem-sucedido. Esse intento discursivo é definido como o movimento de securitização, e, um problema só pode ser considerado securitizado quando a audiência for convencida da excepcionalidade da situação, legitimando as medidas emergenciais de contenção da ameaça. É importante salientar que a securitização não pode ser imposta ou estabelecida através da coerção, é preciso convencer a audiência da existência de uma ameaça que exige medidas emergenciais e muitas vezes extraordinárias. Caso isso não aconteça, o que ocorre é um movimento de securitização mal sucedido (WÆVER et al, 1998, p.26). Com base nessa concepção percebe-se que a teoria da securitização refere-se a democracias liberais, nas quais o agente securitizante possui margem de manobra discursiva e a audiência é detentora da liberdade de aceitá-la ou não. $\mathrm{O}$ ato de segurança é negociado internamente entre o agente e a audiência, de maneira que é concedido ao primeiro o direito de violar as regras, desde que garanta a sobrevivência da unidade. Concede-se caráter prioritário e imediato ao tema securitizado, construindo um entendimento compartilhado da iminência do perigo a partir dos atos de fala (WÆVER et all, 1998, p.24).

No ato de fala é imprescindível que haja a indicação de um ameaça existencial, requerendo ações emergenciais e medidas extraordinárias. A audiência deve invariavelmente aceitar e entender essa construção semântica e legitimar a ação do ator, 
mesmo que essa atue fora dos procedimentos da política normal. Quando há uma persistência das ameaças, a securitização passa a ser institucionalizada. Esse fato que pode ser observado na Guerra ao Terror de Bush, pois o combate ao terrorismo foi incorporado à nova doutrina de segurança dos Estados Unidos em 2002, a Doutrina Bush. Essa institucionalização não faz com que haja um retorno para a esfera da política normal, pelo contrário, as ações continuam seguindo uma lógica extraordinária.

Para os autores, a segurança não deveria ser vista como positiva, fundamentada pela ideia de que quanto mais segurança no mundo melhor. Deve-se inverter essa concepção, deixando-se de idealizar a segurança como um objetivo final das nações ou indivíduos. A segurança significa que houve um fracasso de se resolver o problema de maneira satisfatória através da política, demandando medidas extraordinárias e abrindo espaço para ações isentas de responsabilidade social com o problema. Logo, as questões securitizadas deveriam ser novamente politizadas e, assim, debatidas e administradas por meio do aparato político burocrático, evitando a ascensão de interesses de grupos específicos no conduzir das questões securitárias. Wæver defende então o processo de des-securitização política como a forma mais adequada para a resolução dos problemas de segurança (WÆVER et all, 1998, p.28-29).

Transpondo essa análise para o cenário político dos Estados Unidos pós 11 de Setembro, é visível como o governo norte-americano apresentou o terrorismo como uma ameaça existencial e fez uso da securitização para justificar as guerras preventivas empreendidas no Oriente Médio. Em vista disso, a próxima seção desse artigo se concentrará nos discursos de George W Bush e o processo de securitização do terrorismo.

\section{GEORGE W. BUSH E A CONSTRUÇÃO DO TERRORISMO COMO AMEAÇA MUNDIAL ATRAVÉS DOS ATOS DE FALA}

Compreendendo a importância da construção discursiva das ameaças para a fixação de uma temática como prioridade securitária de um país, nesta última seção do trabalho, nos debruçaremos sobre os discursos de George W. Bush após os ataques terroristas de 2001, buscando identificar elementos securitizantes a respeito do terrorismo. Para este fim, os discursos de Bush são entendidos como atos de fala e 
movimentos de securitização, que culminaram na Guerra ao Terror e consequentes invasões do Afeganistão (2001) e Iraque (2003).

A retórica do chefe de Estado norte-americano será analisada a partir do aparato conceitual contido na teoria da securitização, procurando observar como foi articulado em sua fala o estabelecimento de uma ameaça emergencial e existencial com força suficiente para legitimar medidas extraordinárias em resposta ao 11 de setembro. Para tal, analisaremos inicialmente o Pronunciamento à Nação de 11 de setembro de 2001, a fala do presidente no dia 07/10/2001 sobre a invasão do Afeganistão, o Pronunciamento direcionado a Assembleia Geral das Nações Unidas em 11/10/2001 e o Discurso de West Point de Junho de 2002, no qual Bush define as premissas da nova política externa e de segurança do seu país, a Doutrina Bush.

O discurso é utilizado como uma representação social, na qual o sujeito constrói a sua identidade e concomitantemente atua na formação do mundo e das identidades de outros indivíduos. Isso acarreta "uma relação dialética entre o discurso e a estrutura social, existindo mais geralmente tal relação entre a prática social e a estrutura social: a última é tanto uma condição como um efeito pra primeira" (FAIRCLOUGH, 2001, p.91). Dessa maneira, o discurso mais do que representar o mundo social, também lhe confere significado e é ressignicado pelo meio ao qual está inserido, através de um exercício constante de co-constituição.

\footnotetext{
0 discurso é a linguagem enquanto prática social determinada por estruturas sociais (as regras e/ou conjuntos de relações de transformação organizadas como propriedades dos sistemas sociais). Ao aceitar essa premissa, estamos aceitando também que a estrutura social determina, dessa forma, as condições de produção do discurso (LUPICINIO, 2004, p.149).
}

Entendendo o discurso como uma prática política, que "estabelece, mantém e transforma as relações de poder e as entidades coletivas (classes, blocos, comunidades, grupos) entre as quais existem relações de poder" (FAIRCLOUGH, 2001, p.94), é possível apreender a importância da análise dos discursos relacionados à segurança internacional. O discurso é ao mesmo tempo complementar a realidade e constitutivo da mesma. Ele representa interesses, legitima intenções e cria necessidades. E a contribuição da teoria da securitização está em possibilitar uma melhor compreensão dos processos que elevam 
uma temática como problema de segurança. A relevância concedida aos Atos de Fala nos permite analisar como esse processo se desenvolve.

Relembrando que a securitização é o movimento que eleva a política para além das regras e procedimentos regulatórios e éticos, e foi justamente isso que Bush e sua equipe de governo procuraram fazer ao longo do seu primeiro mandato. Mais do que punir os responsáveis pelos ataques, os Estados Unidos construíram o imaginário sobre o novo inimigo mundial e passaram a perseguir as organizações terroristas e aos Estados entendidos como apoiadores e financiadores do terrorismo, referidos por Bush como o Eixo do $\mathrm{Mal}^{6}$. Através da securitização do terrorismo foi alicerçada a consolidação de uma nova política de segurança que se apoiava no princípio das Guerras Preventivas.

Contrariamente a conflitos anteriores (Guerra do Golfo, por exemplo), em que os EUA buscaram legitimar sua ação intervencionista através de alianças estratégicas com outros países ou entidades multilaterais, o 11 de setembro, ataque direto à própria essência do "ser" americano, trouxe, na percepção de que constituía uma luta entre o bem e o mal, elementos que legitimavam uma reação imediata e unilateral. A rede de apoio e solidariedade que rapidamente se construiu em torno dos EUA não foi, nesse sentido, propriamente reivindicada por aquele país, mas sim esperada como fato natural (BARBOSA, 2002, p.77).

A teoria da securitização entende que as constelações políticas devem ser analisadas juntamente com os Atos de Fala. Logo, é imprescindível que se observe a composição política do governo americano em 2001, sob a presidência de George W. Bush. A orientação ideológica do gabinete era em sua maioria neoconservadora, remanescente dos anos 1980 e das gestões de Ronald Reagan, Richard Nixon e Bush pai. Os nomes mais proeminentes presentes na administração de Bush eram o de Dick Cheney, Donald Rumsfeld, Condoleezza Rice7, foram Vice-Presidente, Secretário de Defesa e Secretária de Estado (PECEQUILO, 2005, p.355).

O neoconservadorismo oferece um conjunto de ideias com uma visão específica sobre a política externa norte-americana (TEIXEIRA, 2007, p.95) Essa visão é marcada pelo internacionalismo, pelo unilateralismo e pela centralidade das capacidades militares americanas como forma de projeção de poder. Os neoconservadores defendem "um

\footnotetext{
6 George W. Bush passou a utilizar a expressão "Eixo do Mal" para se referir aos três países que representavam, segundo o então presidente norte-americano, uma grande ameaça ao mundo e à segurança dos EUA, sendo eles Irã, Iraque e Coreia do Norte. Bush acusava esses países de desenvolverem armas de destruição em massa e de patrocinar o terrorismo regional e global. Cuba, Líbia e Síria também foram incluídos nesse grupo.

${ }^{7}$ Esse grupo ficou conhecido como os Falcões Neoconservadores.
} 
unilateralismo com interesses globais, visando a manutenção e preservação da ordem internacional estabelecida através do apoio ativo à democracia por parte dos Estados Unidos" (TEIXEIRA, 2007, p.87-88). Com relação àadministração de George W Bush nos primeiros meses na Casa Branca Pecequilo observa que:

[...] um acontecimento inédito pareceu trazer-lhe uma inflexão: 11/09/2001. Neste dia, pela primeira vez em sua história, os EUA foram atacados em seu território continental por um grupo terrorista, atingindo duas de suas principais cidades e símbolos de poder: as torres gêmeas de Nova Iorque e o Pentágono em Washington. Realizado de maneira simples, com o sequestro de aviões de carreira, os atentados foram eficientes em destruir a última sensação de normalidade que permanecia no mundo, colocando em questão o poder militar da superpotência restante. Percebido por muitos como uma resposta a Bush, os ataques, contudo, eram parte de um processo de longo prazo muito maior, característico de contestação hegemônica (PECEQUILO, 2005, p.367).

Após os atentados de 11 de setembro em 2001 o pensamento e a política neoconservadora passaram a defender a ideia de guerras preventivas (TEIXEIRA, 2007, p.95). Dessa maneira, o cenário político estadunidense corroborou com o processo de securitização do terrorismo. As premissas orientadoras das políticas neoconservadoras convergiram com as respostas adotadas pelos Estados Unidos, sobretudo pela comoção causada pelos atos terroristas e pela retórica implacável dos atores envolvidos com relação à ameaça terrorista.

Os ataques de 11 de setembro foram repletos de simbolismo e o fato por si só já seria suficiente para justificar respostas duras por parte dos EUA. A imagem dos aviões se chocando contra os prédios, símbolos do poder econômico do país, estremeceu as bases de segurança norte-americanas, deu margem para o fortalecimento do patriotismo e do preconceito. A representação do terrorismo como ameaça existencial aos Estados Unidos e a toda a civilização ocidental está presente na argumentação de Bush no seu primeiro pronunciamento à nação após os ataques, no qual o governante enfatizava:

Hoje, os nossos concidadãos, o nosso modo de vida, a nossa própria liberdade se viram sob o ataque de uma série de atos terroristas deliberados e mortais. As vítimas estavam em aviões ou em seus trabalhos; secretários, empresários e mulheres, trabalhadores militares e federais; mães e pais, amigos e vizinhos. Milhares de vidas que subitamente terminaram por causa do mal, de atos desprezíveis de terror (BUSH, 2001, p.57). ${ }^{8}$

\footnotetext{
8 Tradução livre: "Today, our fellow citizens, our way of life, our very freedom came under attack in a series of deliberate and deadly terrorist acts. The victims were in airplanes, or in their offices; secretaries, businessmen and women, military and federal workers; moms and dads, friends and neighbours. Thousands of lives were suddenly ended by evil, despicable acts of terror".
} 
Percebe-se que Bush buscou não só retratar o inimigo que estava se formando, mas também enfatizar a vulnerabilidade dos indivíduos frente a essa nova ameaça. Quando ele denota que pessoas comuns tiveram as suas vidas arrancadas pelo terror, ele reforça a premissa de que qualquer indivíduo pode ser alvo de um grupo terrorista, logo, ninguém estaria seguro. Nesse mesmo discurso e amparado pela crença de que o terrorismo se conforma a partir de ataques deliberadamente aleatórios, o estadista estabelece a possibilidade e iminência de novos ataques terroristas no país. Isso fortalece a percepção de ameaça na audiência. Buscava legitimar as medidas tomadas pelos EUA para responder aos atentados, em vista da ameaça provocada pelo terrorismo e justificava medidas fora da esfera normal da política, como o Ato Patriota.

No próximo segmento desse primeiro discurso, observa-se a maneira através da qual o governo lidaria com a situação e com os responsáveis pelos atentados, incluindo os regimes que se identificavam com esses grupos.

A busca está em andamento para encontrar aqueles que estão por trás desses atos malignos. Eu já dirigi todos os recursos das nossas comunidades de inteligência e da lei para encontrar os responsáveis e levá-los à justiça. Não faremos distinção entre os terroristas que cometeram esses atos e aqueles que os protegem (BUSH, 2001, p.58). ${ }^{9}$

Ao dizer que o povo dos Estados Unidos resistiria ao terror e caracterizar a sua luta contra o terrorismo como a "luta pelo bem", Bush mais uma vez assegura que o seu país iria assumir a posição de liderança no esforço mundial contra o terrorismo, recorrendo ao discurso emocional e contundente sobre os fatos como reforço da importância de se lidar com a questão com medidas emergenciais e de caráter militar.

Em discurso para a Nação no dia 07/10/2001, Bush falou sobre a invasão do Afeganistão pelos Estados Unidos, destacando:

Sob as minhas ordens, os militares dos Estados Unidos iniciaram ataques contra
os campos de treinamento de terroristas da Al Qaeda e instalações militares do
regime talibã no Afeganistão. Estas ações cuidadosamente estão orientadas e são
projetadas para interromper o uso do Afeganistão como uma base terrorista de
operações, e atacar a capacidade militar do regime talibã. (BUSH, 2001, p.75). ${ }^{10}$

9 Tradução livre: "The search is underway for those who are behind these evil acts. I've directed the full resources of our intelligence and law enforcement communities to find those responsible and to bring them to justice. We will make no distinction between the terrorists who committed these acts and those who harbour them."

10 Tradução livre: "On my orders, the United States military has begun strikes against al Qaeda terrorist training camps and military installations of the Taliban regime in Afghanistan. These carefully targeted 
O presidente legitima as suas ações no cenário internacional a partir dos ataques de 11 de setembro, logo, já podemos constatar a conflagração das referidas medidas extraordinárias da teoria da securitização. Bush, enquanto agente securitizante, caracterizou o terrorismo como uma ameaça emergencial para os Estados Unidos e para toda a humanidade. A invasão do Afeganistão e derrubada do regime talibã foi entendida nesse contexto como necessária. Ao qual, Bush, ainda diz:

\begin{abstract}
Esta ação militar é apenas uma parte da nossa campanha contra o terrorismo, outra frente em uma guerra que une o meio da diplomacia, da inteligência, do congelamento de ativos financeiros e as detenções de terroristas conhecidos por agentes da lei em 38 países [...] hoje vamos nos concentrar no Afeganistão, mas a batalha é mais ampla. Cada nação tem uma escolha a fazer. Neste conflito, não há terreno neutro. Se qualquer governo patrocina esses bandidos e assassinos de inocentes, eles se tornaram bandidos e assassinos também. (BUSH, 2001, p.76). ${ }^{11}$
\end{abstract}

Apreende-se do trecho acima que Bush se direciona não somente à nação norteamericana, como também aos líderes mundiais, elevando o terrorismo como uma ameaça existencial compartilhado por todos os países do globo. É notável também a articulação de diversas esferas da vida política e em sociedade para combater os grupos terroristas, fazendo com que a questão seja securitizada em diversos setores além do militar. Outro ponto relevante que pode ser extraído da leitura desse trecho é a construção argumentativa do estadista, que deixa claro que o terrorismo é uma ameaça existencial, assumindo um tom agressivo e uma política de tolerância zero para com os Estados que não entendem a temática da mesma forma que o seu governo. Dessa forma, os Estados Unidos deixam claro que passariam a ser a ameaça existencial para aqueles regimes que apoiassem e protegessem organizações e líderes terroristas.

Um dos discursos mais emblemáticos de George W. Bush para se perceber a securitização do terrorismo e a maneira como ela foi incorporada por suas políticas de segurança, é a fala de West Point, em junho de 2002, através da qual são apresentados os princípios da Doutrina Bush. Essa preleção de Bush é direcionada aos graduandos de West

actions are designed to disrupt the use of Afghanistan as a terrorist base of operations, and to attack the military capability of the Taliban regime."

${ }^{11}$ Tradução livre: "This military action is a part of our campaign against terrorism, another front in a war that has already been joined through diplomacy, intelligence, the freezing of financial assets and the arrests of known terrorists by law enforcement agents in 38 countries [...] Today we focus on Afghanistan, but the battle is broader. Every nation has a choice to make. In this conflict, there is no neutral ground. If any government sponsors the outlaws and killers of innocents, they have become outlaws and murderers, themselves." 
Point e a comunidade militar, contudo, percebe-se que a narrativa do presidente objetiva atingir um maior alcance, se alongando para todo o globo.

Ao defender a paz, estamos diante de uma ameaça sem precedentes. Inimigos do passado necessitavam de grandes exércitos e grandes capacidades industriais para pôr em perigo o povo americano e a nossa nação. Os ataques de 11 de setembro precisaram de apenas alguns milhares de dólares nas mãos de uns poucos homens maus e desiludidos. Todo o caos e o sofrimento que causaram custaram menos que o preço de um único tanque. 0 perigo não passou. Este governo e o povo americano estão no relógio, estamos prontos, porque sabemos que os terroristas têm mais dinheiro e mais homens e mais planos (BUSH, 2002, p.127) ${ }^{12}$

A ameaça do terrorismo é caracterizada como algo novo, de modo que os EUA deveriam buscar novos métodos de lidar e resolver a problemática. Bush destaca que os terroristas não precisam de muitos recursos para causar grandes estragos e que o perigo, mesmo em 2002, ainda era iminente para a nação norte-americana. Há um alongamento no problema do terrorismo para justificar a sua institucionalização por meio da Doutrina Bush. A inevitabilidade de novos ataques é descrita justamente para defender que o problema não pode ser resolvido pelos mecanismos da política normal. Assim, ele enfatiza:

No entanto, a guerra contra o terror não será vencida na defensiva. Devemos levar a batalha para o inimigo, perturbar os seus planos e confrontar as piores ameaças antes que elas surjam. No mundo em que entramos o único caminho para a segurança é o caminho da ação. E esta nação vai atuar (BUSH, 2002, p.128) ${ }^{13}$.

Bush faz alusão às guerras preventivas, um dos principais métodos utilizados após os atentados de 11 de setembro pelo país. 0 terrorismo foi securitizado a tal ponto que o governo norte-americano o utilizou como ferramenta legitimadora da execução dos seus interesses no Oriente Médio. Essa política dura acabou fortalecendo grupos radicais na região, indo de encontro com a crítica de Waever sobre o excesso de securitização.

\footnotetext{
12 Tradução livre: "In defending the peace, we face a threat with no precedent. Enemies in the past needed great armies and great industrial capabilities to endanger the American people and our nation. The attacks of September the 11th required a few hundred thousand dollars in the hands of a few dozen evil and deluded men. All of the chaos and suffering they caused came at much less than the cost of a single tank. The dangers have not passed. This government and the American people are on watch, we are ready, because we know the terrorists have more money and more men and more plans."

${ }^{13}$ Tradução livre: "Yet the war on terror will not be won on the defensive. We must take the battle to the enemy, disrupt his plans, and confront the worst threats before they emerge. In the world we have entered, the only path to safety is the path of action. And this nation will act."
} 
A partir da exposição das falas de Bush fica evidente que o terrorismo foi alçado como prioridade na agenda de segurança internacional através dos processos intersubjetivos de construção de ameaças existentes nos atos de fala do presidente norteamericano. Os Estados Unidos possuíam as capacidades necessárias, sejam elas materiais ou subjetivas, para concluir o movimento de securitização da al-Qaeda e demais grupos considerados terroristas com sucesso, exportando a sua agenda de combate ao terrorismo para o mundo.

\section{CONCLUSÃo}

Os discursos utilizados nesse artigo exemplificam como se deu a construção narrativa do terrorismo como ameaça emergencial pelo presidente George W. Bush e consequente institucionalização da securitização do fenômeno através da Guerra ao Terror. Os atentados foram utilizados para justificar uma séria de intervenções militares, destacando-se as guerras no Afeganistão e Iraque, mas também serviram para fortalecer a campanha norte-americana contra o programa nuclear iraniano. Internamente, houve a aprovação do Ato Patriota, assinado por Bush em 26 de Outubro de 2001, permitindo através de decreto que as agências de inteligência interceptassem ligações telefônicas sem autorização judicial. Outro aspecto importante foi a convergência entre a retórica presidencial e o apoio da audiência, tanto da população, como da mídia norte-americana. Bush se utilizou de um padrão retórico historicamente bem sucedido no país, a representação do "outro" como diretamente oposto aos ideais estadunidenses, facilitando sua descrição como ameaça, legitimando assim as suas ações no Oriente Médio e concretizando de maneira bem-sucedida o seu movimento de securitização.

As relações subjetivas indicadas por Waever et al entre a construção de uma ameaça existencial, a conflagração de medidas extraordinárias como resposta ao problema apresentado como ameaça existencial a um objeto de referência e a relação da unidade com as regras da política normal possibilitam um olhar crítico sobre a formulação da narrativa a respeito do terror realizada por Bush. Permitindo que se possa analisar como a linguagem como ferramenta legitimadora é de suma importância para o campo de estudos da segurança internacional, sobretudo, em democracias liberais. A extensão dos empreendimentos de guerra realizada na gestão Bush necessitava de justificação frente 
ao cidadão norte-americano e também a outros líderes mundiais, logo, a securitização do terrorismo forneceu o aparato ideológico ideal para a legitimação da Guerra ao terror.

\section{REFERÊNCIAS BIBLIOGRÁFICAS}

ADLER, Emanuel. O construtivismo no estudo das Relações Internacionais. Lua Nova, São Paulo, n. 47, p.201-352, 1999. Disponível em: <http://www.scielo.br/pdf/ln/n47/a11n47>. Acesso em: 24 out. 2016.

BALDWIN, David. Security Studies and the End of the Cold War. World Politics. Montreal, Canadá. vol. 48, nº 9, p.117-141. Outubro, 1995.

BARBOSA, Rubens Antônio. Os Estados Unidos pós 11 de setembro de 2001: implicações para a ordem mundial e para o Brasil. Revista Brasileira de Política Internacional. Brasília, Brasil. vol.45, no 1, p.72-91. 2002.

BUSH, George W (2001). Addres to the Nation on the September 11 Atacks. In: Select Speechs of President George W. Bush: 2001-2008. White House, p.57-58. 2009.

BUSH, George W (2001). Address to the Nation on Operation in Afeghanistan. In: Select Speechs of President George W. Bush: 2001-2008. White House, p.75-78. 2009.

BUSH, George W (2001). Address to the United Nations General Assembly In: Select Speechs of President George W. Bush: 2001-2008. White House, p.83-90. 2009.

BUSH, George W (2002). West Point Commencement. In: Select Speechs of President George W. Bush: 2001-2008. White House, p.125-132. 2009.

BUZAN, Barry. People, State, and Fear: An Agenda for International Security Studies in the Post Cold War. Wheatsheaf Books LTD: Brighton, Sussex. 1983.

BUZAN, Barry; HANSEN, Lene. A evolução dos estudos de segurança internacional. Ed. Unesp: São Paulo. 2012.

CHECKEL, Jeffrey T. The Constructivist Turn in International Relations Theory. World Politics, Cambridge, $\quad$ v. $\quad 50$, n. 2, p.324-348, jan. 1998. Disponível em: <http://n.ereserve.fiu.edu/010030866-1.pdf>. Acesso em: 23/06/2017

DUQUE, Marina Guedes. O Papel de Síntese da Escola de Copenhague nos Estudos de Segurança Internacional. Contexto Internacional. Rio de Janeiro, Brasil. Vol. 31, noㅜ , p.459-501. Setembro/Dezembro, 2009.

FAIRCLOUGH, Norman. Discurso e mudança social. Brasília: UnB, 2001.

FINGUERUT, Ariel. A influência do pensamento neoconservador na política externa de George W. Bush. 150 f. Araraquara, São Paulo. Dissertação (Mestrado em Sociologia). Faculdade de Ciências e Letras. Universidade Estadual de São Paulo, 2008.

FOX NEWS. Fox News Channel. Acessado em: 12/06/2016 Disponível em: HTTP://www.foxnews.com/world/index.html. 
GRACIA, Tomás Ibáñez. 0 "giro linguístico". In: IÑIGUEZ, Lupicinio (coord.). Manual de análise do discurso em ciências sociais. Petrópolis: Vozes, 2004.

HUYSMANS, Jef. Revisiting Copenhagen: Or, On the Creative Development of a Security Studies Agenda in Europe. European Journal of International Relations. vol. 4, n. 4, p.479-505. Londres, Reino Unido. 1998.

KRATOCHWILL, Friedrisch. Constructivism: what it is (not) and how it matters. p. 80-98. In: Aproaches and Methodologies in the Social Science: pluralist perspectivie. (Ed) KEATING, Michal; PORTA, Donatella Della. Cambridge University Press. 2008.

ONUF, Nicholas. Constructivism: a User's Manual. In: Kubálková et all (eds.). International Relations in a constructed world. New York: M.E.Sharpe. p. 58-78. 1998. PECEQUILO, Cristina Soreanu. Bush II: A ascensão neoconservadora ou o novo declínio? Civitas. Porto Alegre. v. 5, n. 2, p. 353-380. 2005.

RUDZIT, Gunther. O debate teórico em segurança internacional: Mudanças frente ao terrorismo? Civitas. Porto Alegre v. 5 n. 2, p. 297-323. jul.-dez. 2005.

SANTORO, Maurício; BLANCO, Ramon. Segurança, Desenvolvimento e Democracia: Do Trilema da Guerra Fria à Simbiose Contemporânea. In: Renata de Melo Rosa; Carlos Federico Domínguez Avila. (Org.). América Latina no Labirinto Global: Economia, Política e Segurança. 1ed.Curitiba: Editora CRV, 2012, v. , p. 241-256.

TANNO, Grace. A contribuição da Escola de Copenhague aos estudos de segurança internacional. Contexto Internacional, Rio de Janeiro, vol.25, n.01, p. 47-80. 2003.

TEIXEIRA, Carlos Gustavo Poggio. Quatro temas fundamentais do pensamento neoconservador em política externa. Revista Brasileira de Política Internacional. Brasília. V. 50, n. 2, p. 80-96. 2007.

WÆVER, Ole. Securitization and Desecuritization. (In) Ronnie Lipschutz (ed.), On Security. p. 46-87.Nova Iorque, Columbia University Press. 1998. PDF.

WÆVER, Ole; BUZAN, Barry; WILDER, Jaap. Security: A New Framework for Analysis. Londres, Lynne Rienner Publishers. 1998.

ZEHFUSS, Maja. Constructivism in International Relations: The politics of reality. Cambridge University Press, 2004. 